\title{
Using aortic arch short axis views during transesophageal echocardiographic examination facilitates right ventricular assist device imaging
}

Alyssa Tutunjian ${ }^{1}$, Jamel Ortoleva ${ }^{2}$, Yong Zhan², Frederick Chen ${ }^{2}$, Gregory Couper ${ }^{2}$, and Masashi Kawabori ${ }^{2}$

${ }^{1}$ Tufts University School of Medicine

${ }^{2}$ Tufts Medical Center

September 25, 2021

\begin{abstract}
Given the increased need for mechanical circulatory support and subsequent development of right ventricular assist devices (RVAD), appropriate imaging needs to be described to facilitate care in patients with cardiogenic shock and heart failure. We present three cases in which the upper esophageal aortic arch short axis (UE AA SAX) view on transesophageal echocardiography (TEE) was utilized to effectively image RVADs: to confirm normal positioning, to detect and guide repositioning, and to visualize malfunction. These cases support the importance of the UE AA SAX TEE view in RVAD outflow imaging and, when obtainable, should be included in routine RVAD assessment.
\end{abstract}

\section{Hosted file}

TEE_SAX_RVAD_JCS_08232021.docx available at https://authorea.com/users/436141/articles/ 538680-using-aortic-arch-short-axis-views-during-transesophageal-echocardiographicexamination-facilitates-right-ventricular-assist-device-imaging

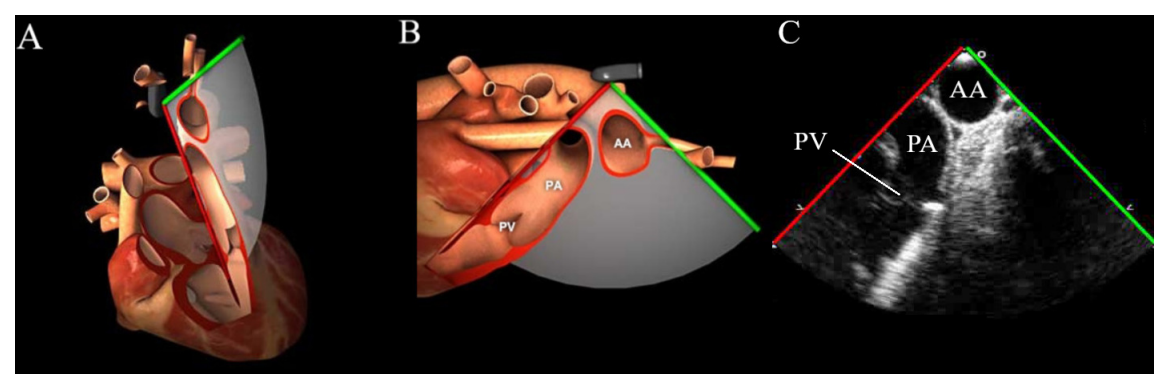



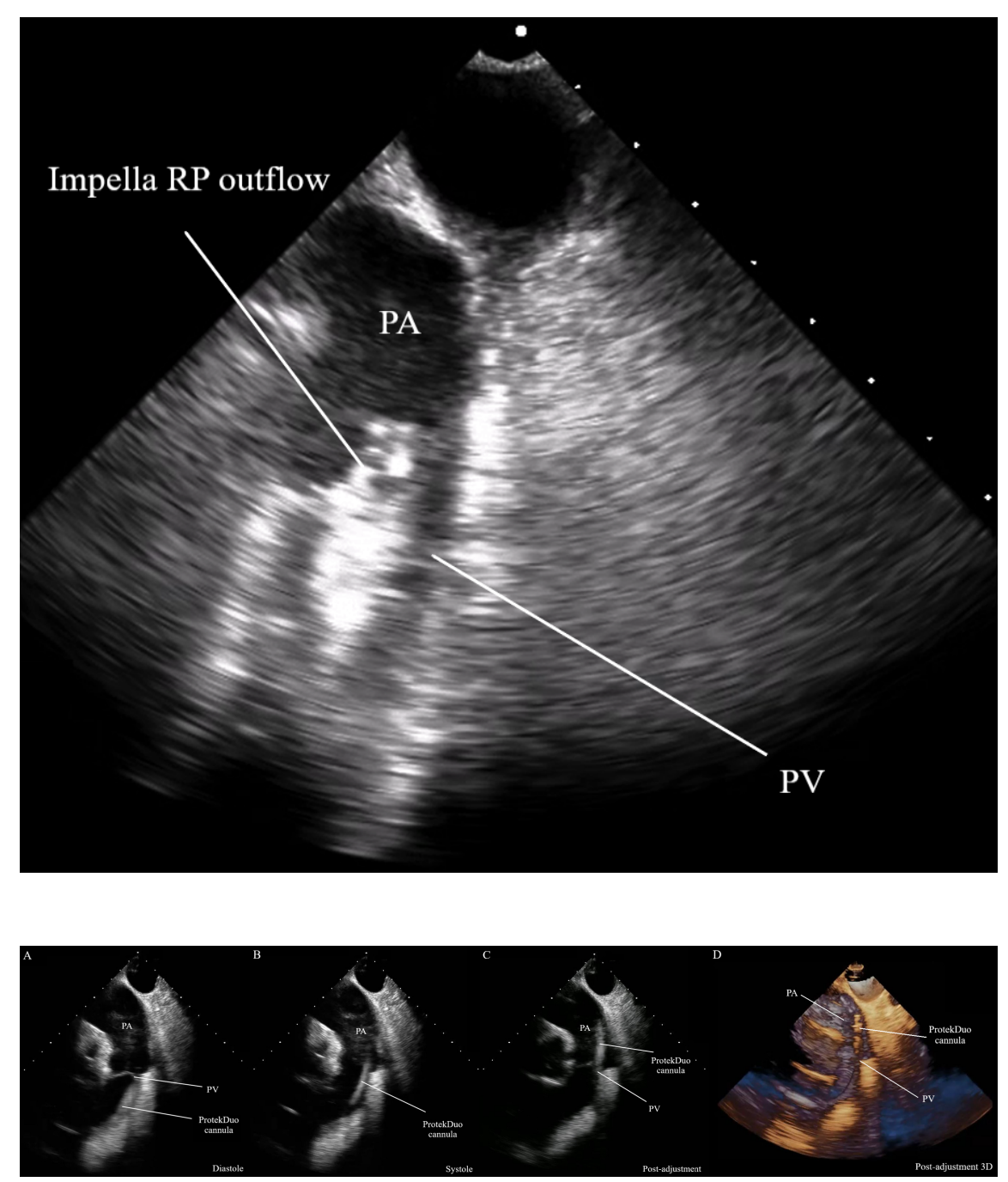


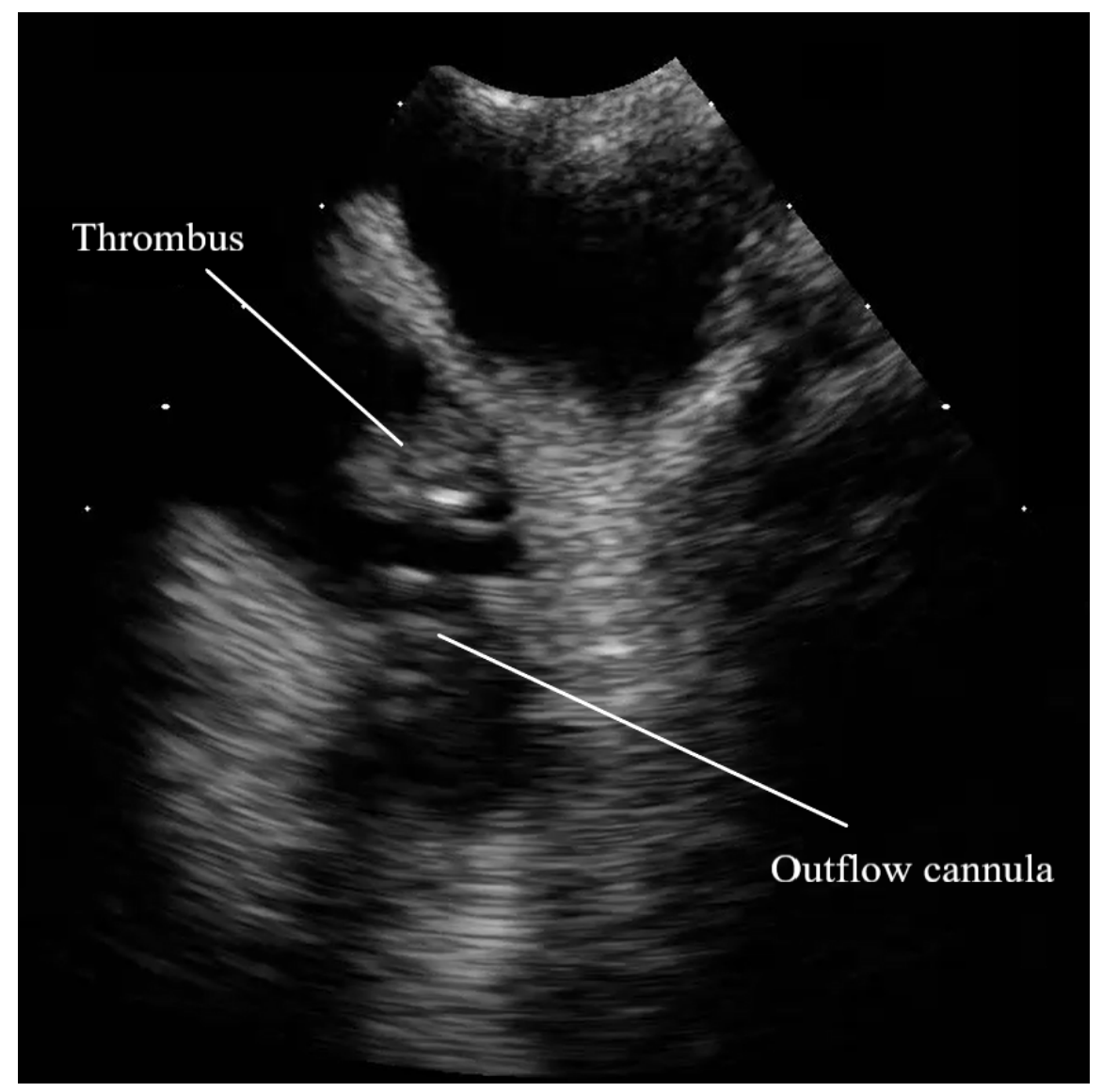

